\title{
Adenosine metabolism and murine strain-specific IL-4-induced inflammation, emphysema, and fibrosis
}

\author{
Bing Ma, ${ }^{1}$ Michael R. Blackburn, ${ }^{2}$ Chun Geun Lee, ${ }^{1}$ Robert J. Homer, ${ }^{3}$ Wei Liu, ${ }^{1}$ Richard A. Flavell, ${ }^{4}$ \\ Lynn Boyden, ${ }^{5}$ Richard P. Lifton, ${ }^{5}$ Chun-Xiao Sun, ${ }^{2}$ Hays W. Young, ${ }^{2}$ and Jack A. Elias ${ }^{1}$

\begin{abstract}
${ }^{1}$ Section of Pulmonary and Critical Care Medicine, Yale University School of Medicine, New Haven, Connecticut, USA. ${ }^{2}$ Department of Biochemistry and Molecular Biology, University of Texas Medical School at Houston, Houston, Texas, USA. 3Department of Pathology, Yale University School of Medicine, New Haven, Connecticut, USA, and Pathology and Laboratory Medicine Service, VA Connecticut Health Care System, West Haven, Connecticut, USA.
\end{abstract} \\ ${ }^{4}$ Department of Immunobiology and ${ }^{5}$ Genetics Department, Yale University School of Medicine, New Haven, Connecticut, USA.
}

\begin{abstract}
To define the factors that control the tissue effects of IL-4, we compared the effects of Tg IL-4 in Balb/c and C57BL/ 6 mice. In the former, IL-4 caused modest eosinophilic inflammation and mild airway fibrosis and did not shorten survival. In C57BL/6 mice, IL-4 caused profound eosinophilic inflammation, airway fibrosis, emphysematous alveolar destruction, and premature death. These differences could not be accounted for by changes in Th2 or Th1 cytokines, receptor components, STAT6 activation, MMPs, or cathepsins. In contrast, in C57BL/6 mice, alveolar remodeling was associated with decreased levels of tissue inhibitors of metalloproteinase $2,-3$, and -4 and $\alpha 1$-antitrypsin, and fibrosis was associated with increased levels of total and bioactive TGF- $\beta 1$. Impressive differences in adenosine metabolism were also appreciated, with increased tissue adenosine levels and $A_{1}, A_{2 B}$, and $A_{3}$ adenosine receptor expression and decreased adenosine deaminase (ADA) activity in C57BL/6 animals. Treatment with ADA also reduced the inflammation, fibrosis, and emphysematous destruction and improved the survival of $\mathrm{C} 57 \mathrm{BL} / 6 \mathrm{Tg}$ animals. These studies demonstrate that genetic influences control IL-4 effector pathways in the murine lung. They also demonstrate that IL-4 has different effects on adenosine metabolism in $\mathrm{Balb} / \mathrm{c}$ and $\mathrm{C} 57 \mathrm{BL} / 6$ mice and that these differences contribute to the different responses that IL-4 induces in these inbred animals.
\end{abstract}

\section{Introduction}

Mus musculus is a complex species composed of several related and variably fertile subspecies. Murine complexity has also been contributed to by mutations that have occurred since laboratory inbreeding began approximately a century ago. As a result, inbred murine strains have been established that differ phenotypically from one another, highlighting the important role of genetic modifiers of diverse biologic processes including growth, appearance, injury, repair, immunity, inflammation, and disease presentation (reviewed in ref. 1). This is nicely illustrated in comparisons of Balb/c and C57BL/6 mice, which differ in many ways, including their ability to eradicate pathogens, generate tissue fibrosis in response to fibrogenic stimuli, respond to airway bronchoconstrictors, and manifest emphysema in response to cigarette smoke (2-11). These strains of mice differ significantly in their ability to manifest Th2 and Th1 immune responses with Balb/c mice, being described as Th2 prone with an enhanced ability to produce IgE and respond to allergens while C57BL/ 6 mice are described as low Th2 responders or Th1-prone mice because of their low IgE production and allergen responses $(4,12-16)$. In accord with this concept, $\mathrm{T}$ cells from $\mathrm{Balb} / \mathrm{c}$ animals produce greater amounts of Th2 cytokines $(4,12-14)$ than cells from C57BL/6 animals. Interestingly, at least for IL-4, this dif-

Nonstandard abbreviations used: ADA, adenosine deaminase; $\alpha 1$-AT, $\alpha 1$-antitrypsin; BAL, bronchoalveolar lavage; CC10, Clara cell $10 \mathrm{kDa}$ protein; COPD, chronic obstructive pulmonary disease; dox, doxycycline; IL-4R, IL-4 receptor; PEG, polyethylene glycol; rtTA, reverse tetracycline transactivator; tet-O, tetracycline operator. Conflict of interest: The authors have declared that no conflict of interest exists. Citation for this article: J. Clin. Invest. 116:1274-1283 (2006). doi:10.1172/JCI26372. ference is not due to a difference in the amount of cytokine produced per cell and instead appears to be the result of the enhanced propensity of Balb/c Th2 cells to commit to IL-4 production (4). Surprisingly, although Th2 responses have clearly definable initiation and effector phases, the possibility that inbred mice also differ in their ability to respond to identical amounts of a given Th2 or Th1 cytokine has not been addressed, and examples of genetic control of cytokine effector pathway activation have not been described.

IL-4 was initially identified as B cell stimulatory factor 1 (BSF1), based on its important role in the stimulation of $B$ cell IgE production (17). It has subsequently been demonstrated to be a pleiotropic cytokine that plays a key role in Th2 inflammatory responses and, in select circumstances, Th2-induced tissue remodeling $(4,17-25)$. Interestingly, in a variety of experimental systems, IL-4 has been demonstrated to mediate remodeling responses such as tissue fibrosis and alveolar remodeling less efficiently than the related Th2 cytokine IL-13 $(18,20,26,27)$. This has led to the present conceptualization that IL-4 plays a major role in the initiation of Th2 inflammation while IL-13 is a major mediator of remodeling at sites of Th2 pathology $(26,28,29)$. Although inbred murine strains differ in their susceptibility to Th2 inflammation and tissue fibrosis, the possibility that IL-4 can have quantitatively and/or qualitatively different effects in different inbred mice has not been assessed.

We hypothesized that genetic factors regulate the tissue responses induced by IL-4 in different inbred murine strains. To address this hypothesis, we generated Tg mice in which IL-4 was overexpressed in a lung-specific fashion on $\mathrm{Balb} / \mathrm{c}$ and $\mathrm{C} 57 \mathrm{BL} / 6$ murine backgrounds and compared the phenotype induced by comparable amounts of $\mathrm{Tg}$ IL-4 in these animals. These studies demonstrate that C57BL/6 and 
A
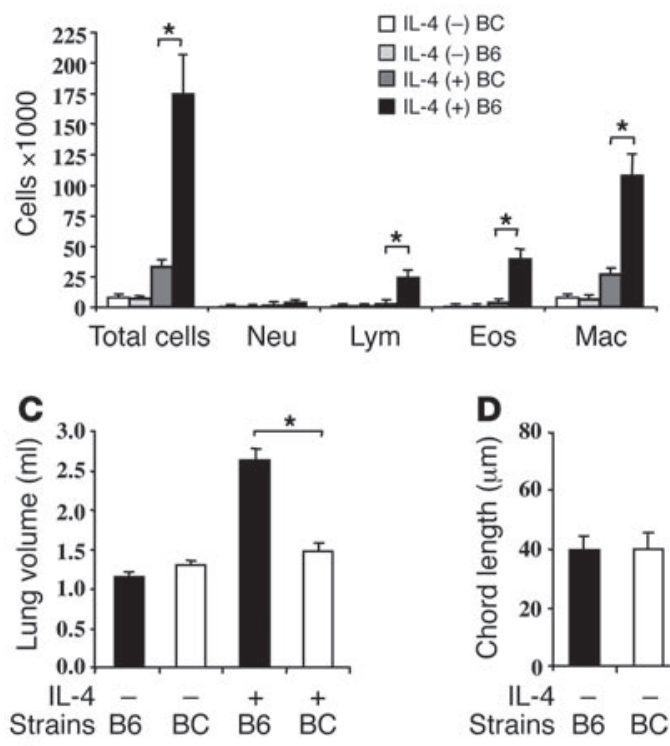

$\mathbf{F}$

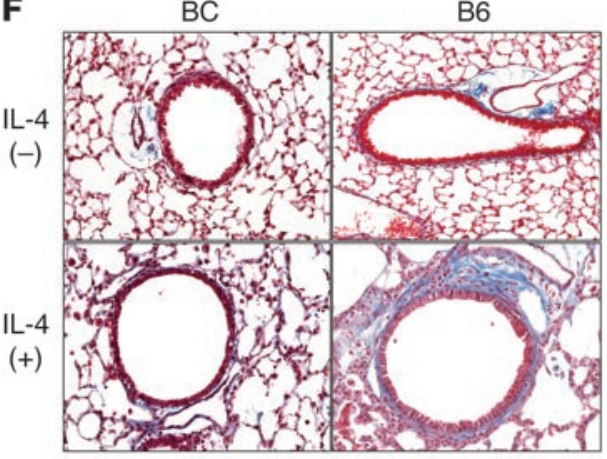

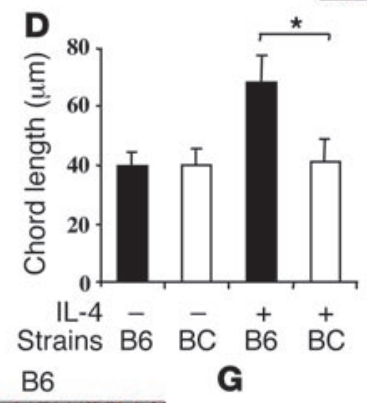

B

$(+)$

$\mathrm{BC}$

$\mathrm{IL}-4$

$(-)$

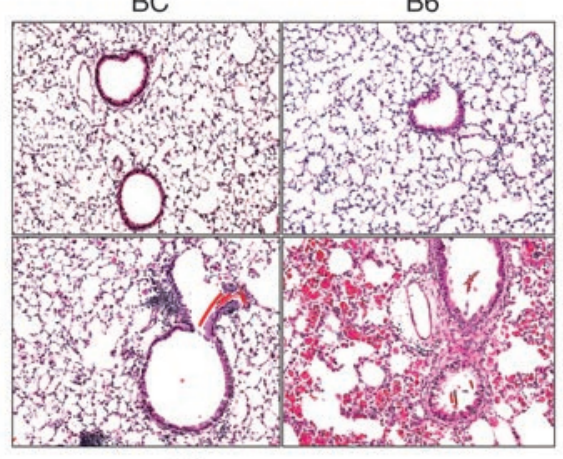

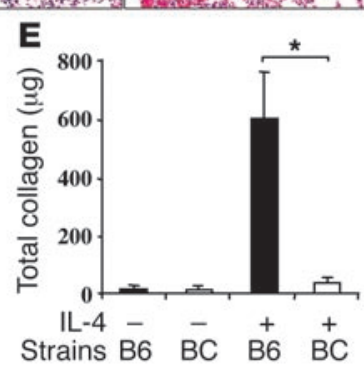

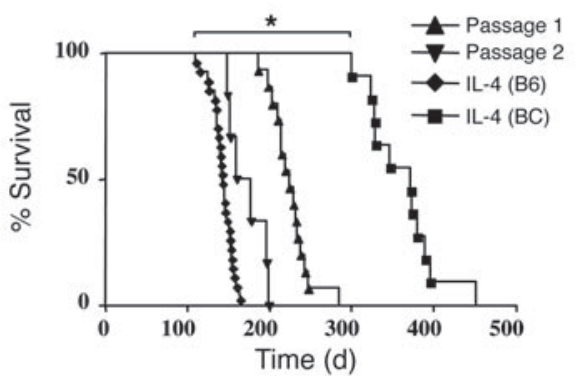

Figure 1

Different phenotypes induced by IL-4 in C57BL/6 and Balb/c mice. IL-4 Tg mice were generated on C57BL/6 (B6) and Balb/c (BC) backgrounds. At 3 months of age, total and differential BAL fluid cell recovery (A), histology (B), lung volume (C), alveolar chord length (D), collagen content (E), and trichrome staining $(\mathbf{F})$ were assessed. The survival of Tgpositive C57BL/6 and Tg-positive Balb/c mice and $F 1$ and F2 backcrosses of Tg-positive Balb/c mice with wild-type C57BL/6 animals is illustrated in $\mathbf{G}$. $\mathbf{B}$ and $\mathbf{F}$ are representative of at least 5 similar experiments. The values in the rest of the figures represent the mean \pm SEM of experiments with a minimum of 5 animals. Neu, neutrophil; lym, lymphocyte; eos, eosinophil; mac, macrophage. ${ }^{*} P<0.01$. Original magnification, $\times 10(B) ; \times 20(\mathbf{F})$.
$\mathrm{Balb} / \mathrm{c}$ mice represent high and low IL-4 effector response strains, respectively, since the inflammatory fibrotic and remodeling effects of IL-4 were significantly greater in C57BL/ 6 than in Balb/c animals. They also define genetic differences in the metabolism of adenosine in these animals and the important role that these differences play in generating these divergent IL-4-induced phenotypes.

\section{Results}

Genetic control of inflammation and remodeling. To determine if murine genetic background regulated IL-4 induced tissue responses, we compared the effects of IL- 4 in Balb/c and C57BL/6 Tg animals. In accord with prior reports, Tg IL-4 in Balb/c mice caused a modest inflammatory response that contained mononuclear cells and eosinophils and modest tissue fibrosis discernible with trichrome and Sircol evaluations (Figure 1) $(18,21)$. Alveolar remodeling and enlargement were not noted in histologic and morphometric assessments (Figure 1, B-D), and all mice survived for a minimum of 1 year (Figure $1 \mathrm{G}$ ). In contrast, in C57BL/ 6 mice, quantitative and qualitative changes in these parameters were readily appreciated. IL-4 was a significantly more potent regulator of bronchoalveolar lavage (BAL) fluid and tissue inflammation in C57BL/ 6 versus Balb/c animals (Figure 1, A and B). IL-4 was also a more potent stimulator of tissue fibrosis in C57BL/ 6 versus $\mathrm{Balb} / \mathrm{c}$ animals. This was readily apparent in biochemical and trichrome evalua- tions (Figure 1, E and F). In addition, in contrast to the normal alveoli in Balb/c mice, IL-4 caused significant alveolar remodeling, with alveolar and lung enlargement and enhanced static compliance in C57BL/ 6 animals (Figure 1, B-D). In keeping with the heightened nature of the IL-4-induced lesions in C57BL/ 6 animals, these $\mathrm{Tg}$ mice died prematurely, with deaths noted in animals that were 110 days old and $100 \%$ of animals being dead by 170 days of age (Figure $1 \mathrm{G}$ ).

To gain additional insight into genetic elements that control IL-4 effector responses, we crossed Balb/c Tg-positive mice serially with wild-type C57BL/ 6 animals and evaluated the phenotype of the offspring after each mating. In these experiments, the phenotype induced by Tg IL-4 changed remarkably. Specifically, by the time that passage 3 mice were generated, IL-4-induced tissue alterations were identical to those seen in Tg-positive C57BL/6 animals (Figure 2 and data not shown).

Overall, these studies highlight impressive differences in IL-4induced inflammation and remodeling in Balb/c and C57BL/6 animals, with inflammation, alveolar remodeling, and fibrosis being significantly more prominent on the latter genetic background.

Inducible Tg modeling of IL-4-induced alveolar remodeling. Genetic manipulations in murine modeling systems can cause alveolar enlargement by blocking lung development or by destroying normally formed alveoli in the mature lung (30-32). To define the extent 


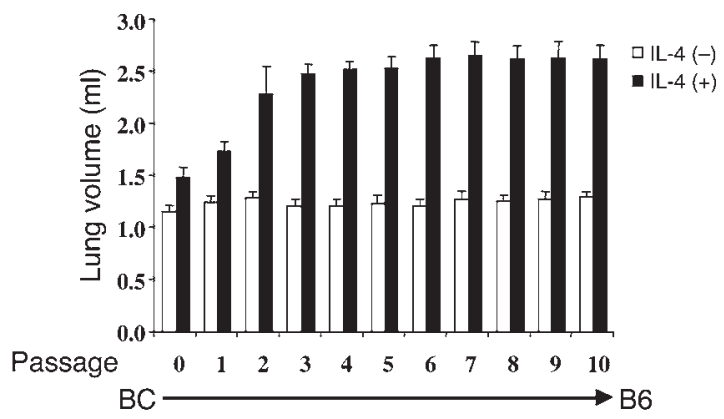

Figure 2

Phenotypic alterations with serial passage. Tg-negative (white bars) and littermate IL-4 Tg-positive mice (black bars) on a Balb/c background were serially bred with wild-type C57BL/6 mice. After each passage, lung volume was assessed in 3-month-old animals. Passage 0 through passage 10 animals are illustrated.

to which each of these responses contributed to the alveolar enlargement in Tg IL-4, we generated C57BL/6 Tg mice in which the IL-4 Tg could be temporally regulated. We then defined the tissue alterations that were induced in these CC10-rtTA-IL-4 mice (CC10, Clara cell $10 \mathrm{kDa}$ protein; rtTA, reverse tetracycline transactivator) when the $\mathrm{Tg}$ was selectively activated in mature adult animals with normally formed lungs. In this setting, IL-4 caused alveolar and lung enlargement and increases in pulmonary inflammation comparable to those seen in CC10-IL-4 animals (Figure 3, A-C, and data not shown). Similar alterations were not seen when IL-4 was only activated in utero (data not shown). Thus, these data demonstrate that Tg IL-4 induces alveolar destruction and emphysematous alterations in lungs from adult C57BL/ 6 mice.

Effects of genetic background on IL-4 production, receptor expression, and STAT6 activation. The heightened IL-4-induced responses in C57BL/ 6 mice could be due to differences in IL-4 production, IL-4 receptor (IL-4R) expression, or IL-4 signaling when compared with $\mathrm{Balb} / \mathrm{c}$ animals. To address these issues, we compared the levels of BAL fluid IL-4, the expression of IL-4R components, and the phosphorylation of STAT6 in Tg-positive mice on both genetic backgrounds. As can be seen in Figure 4, the levels of BAL IL-4 were similar in pure Balb/c and C57BL/6 mice and genetically mixed animals. Similarly, RT-PCR and real-time RT-PCR analysis demonstrated that the levels of expression of IL-4R $\alpha$, the common $\gamma$ chain $\left(\gamma_{c}\right)$, and IL-13R $\alpha 1$, which make up the type I and type II IL-4Rs, were also similar in C57BL/6 and Balb/c Tg animals (Figure 4, B and C). The levels of IL-13R $\alpha 2$, a decoy receptor for IL-13, which competes with IL-4 for binding to the type II IL-4R, were also comparable in Balb/c and C57BL/6 Tg-positive animals (Figure 4, B and C). Lastly, comparable levels of STAT6 phosphorylation were noted in Tg-positive $\mathrm{Balb} / \mathrm{c}$ and $\mathrm{C} 57 \mathrm{BL} / 6$ mice (Figure 4D). When viewed in combination, these studies demonstrate that the different effects of IL-4 in $\mathrm{C} 57 \mathrm{BL} / 6$ and $\mathrm{Balb} / \mathrm{c}$ animals cannot be attributed to differences in IL-4 production, IL-4R expression, or STAT6 activation.

Role of other Th2 and Th1 cytokines. The inflammation, mucus alterations, tissue fibrosis, and alveolar remodeling caused by IL-4 in C57BL/ 6 animals are similar in many ways to those induced by $\mathrm{Tg}$ IL-13 in syngeneic mice (27). Because Th2 cytokines can induce one another $(33,34)$ and Th1 cytokines such as IFN- $\gamma$ can induce alveolar remodeling (35), studies were next undertaken to determine whether IL- 4 stimulated Th 2 or Th 1 cytokines in the murine lung and whether differences in this induction could account for the different effects of IL-4 in C57BL/6 and Balb/c mice. As shown in Figure 5, IL-4 did not induce IL-5, IL-13, IL-9, or IFN- $\gamma$ in C57BL/ 6 or Balb/c animals. Thus, the different effects of IL-4 on these different genetic backgrounds cannot be attributed to a Th2 or Th1 cytokine induction cascade.

Genetic control of protease and antiprotease responses. We reasoned that alterations in proteases and/or antiproteases could explain the differential ability of Tg IL-4 to induce pulmonary emphyse$\mathrm{ma}$ in $\mathrm{C} 57 \mathrm{BL} / 6$ versus Balb/c animals. In wild-type, Balb/c, and C57BL/ 6 mice, the levels of expression of MMP-2, -9, -12, and -14 and cathepsins B, H, K, L, and S were near or below the limits of expression in our assays (Figure 6). In addition, the expression of all of these proteases except for MMP-2 was comparably increased by Tg IL- 4 in both Balb/c and C57BL/ 6 background animals (Figure 6, A and B). Interestingly, although alveolar remodeling was more impressive in C57BL/6 Tg-positive mice, IL-4 induction of MMP- 2 mRNA and protein was less impressive in C57BL/ 6 versus Balb/c animals (Figure 6, A and B, and data not shown).

The levels of mRNA encoding the antiproteases, $\alpha 1$-antitryp$\sin (\alpha 1-\mathrm{AT})$, secretory leukocyte proteinase inhibitor (SLPI), tissue inhibitors of metalloproteinase 1-4 (TIMPs -1, -2, -3, and -4) and cystatin $\mathrm{C}$ were readily apparent and comparably expressed in lungs from wild-type Balb/c and C57BL/6 mice (Figure 6, C and D).

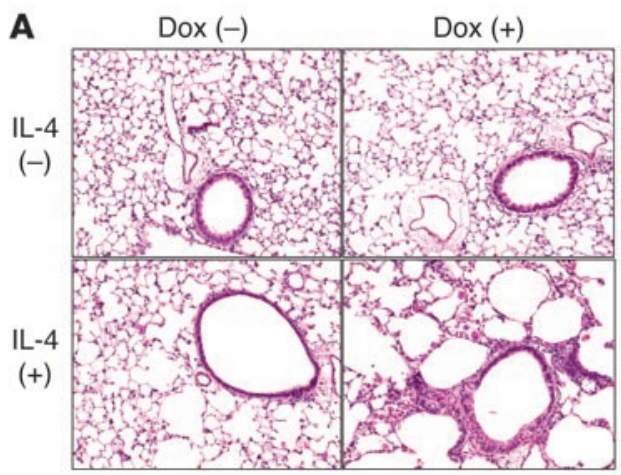

B

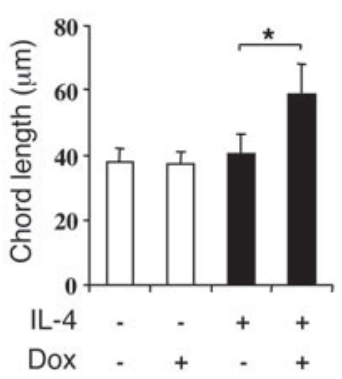

C

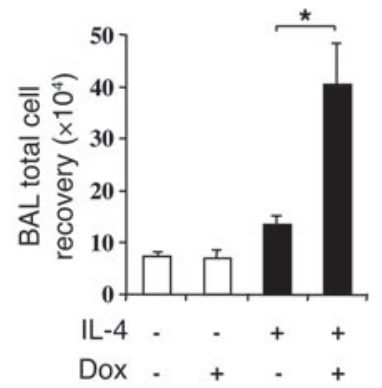

Figure 3

Alveolar remodeling in inducible IL-4 Tg mice. CC10-rtTA-IL-4 mice were generated and randomized to normal water or dox water. They were sacrificed 1 month later, and alveolar histology (A), chord length (B), and BAL fluid cell recovery (C) were assessed. $\mathbf{A}$ is representative of at least 5 similar experiments. The values in $\mathbf{B}$ and $\mathbf{C}$ are the mean \pm SEM of evaluations in a minimum of 5 mice. ${ }^{*} P<0.01$. Original magnification, $\times 10$. 
A

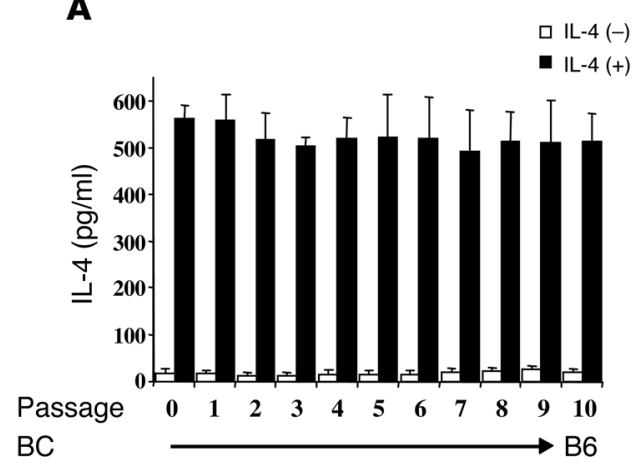

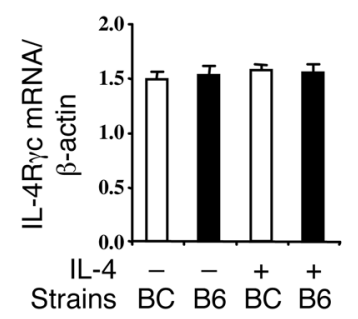

B
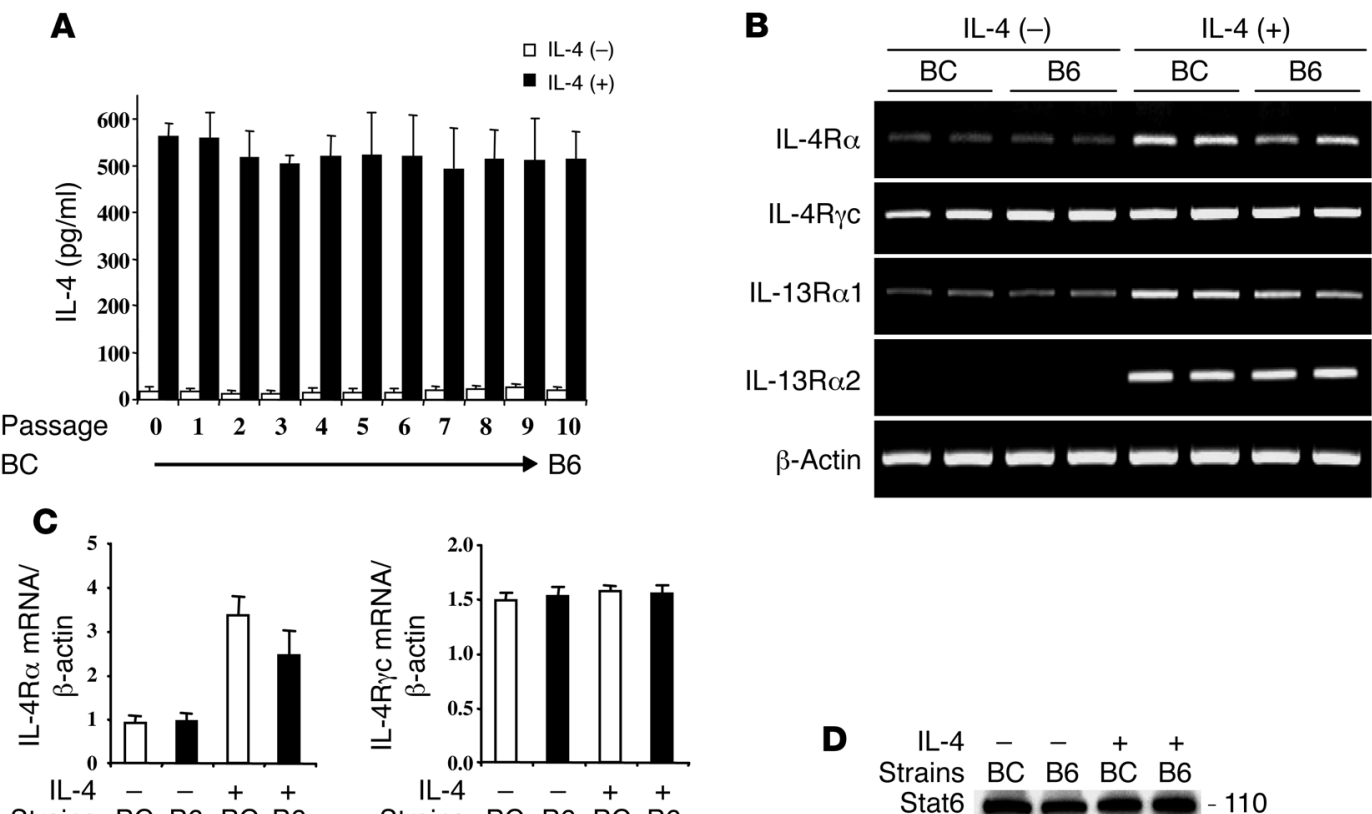

Strains BC B6 BC B6

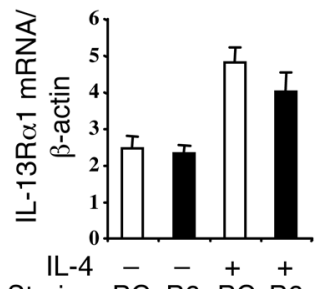

Strains BC B6 BC B6

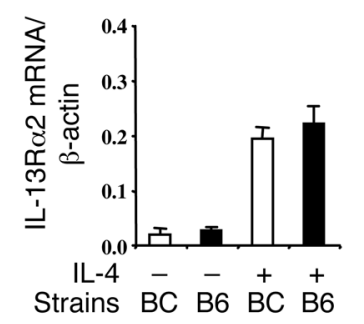

Strains BC B6 BC B6

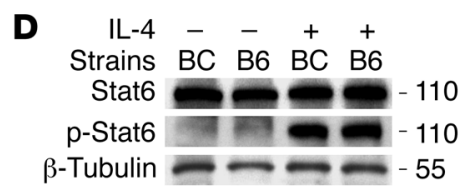

Interestingly, in Balb/c mice, IL-4 increased the expression of TIMP-1, TIMP-3, and TIMP-4 (Figure 6C). In contrast, in C57BL/6 Tg mice, IL-4 caused a comparable increase in TIMP-1, weakly stimulated TIMP- 3 and -4 , and inhibited TIMP- 2 and $\alpha 1$-AT to levels below those in wild-type animals (Figure 6, C and D). When viewed in combination, these studies demonstrate that IL-4 differentially regulates TIMPs and $\alpha 1-\mathrm{AT}$ in $\mathrm{C} 57 \mathrm{BL} / 6$ and Balb/c animals.

Genetic control of TGF- $\beta 1$. TGF- $\beta 1$ is a well-documented mediator of physiologic and pathologic tissue fibrosis. Thus, studies were undertaken to determine if IL-4 regulated the production and activation of TGF- $\beta$ and if differences in these events were noted in $\mathrm{C} 57 \mathrm{BL} / 6$ and $\mathrm{Balb} / \mathrm{c}$ mice. In wild-type animals, levels of total and bioactive TGF- $\beta 1$ were noted that were near or below the limits of our detection assays. In contrast, elevated levels of total and spontaneously bioactive TGF- $\beta$ were readily appreciated in BAL fluids from $\mathrm{Tg}$ mice from both murine strains (Figure 7 ). Interestingly, the levels of total and bioactive TGF- $\beta 1$ were significantly greater in BAL fluids from C57BL/6 than Balb/c Tg animals (Figure 7). Thus, IL- 4 is a more potent stimulator and activator of TGF- $\beta 1$ in $\mathrm{C} 57 \mathrm{BL} / 6$ versus Balb/c Tg animals.

Genetic control of adenosine metabolism. Studies were next undertaken to determine whether IL-4 regulated adenosine metabolism differently in $\mathrm{C} 57 \mathrm{BL} / 6$ and $\mathrm{Balb} / \mathrm{c}$ animals. In these studies, we quantitated the levels of adenosine and adenosine deaminase (ADA) activity and the expression of adenosine receptors in wildtype and $\mathrm{Tg}$ mice. The adenosine assessments revealed impressive increases in the levels of adenosine in lungs from C57BL/6 Tg mice (Figure 8A). IL-4 concomitantly decreased the levels of ADA activ- ity and increased the levels of mRNA encoding the $A_{1}, A_{2 B}$, and $\mathrm{A}_{3}$ adenosine receptors without altering $\mathrm{A}_{2 \mathrm{~A}}$ expression (Figure 8, $B$ and C). In contrast, IL-4 did not cause comparable increases in adenosine, did not inhibit ADA activity, and did not alter the expression of the $A_{1}, A_{2 B}$, or $A_{3}$ receptors in $\mathrm{Balb} / \mathrm{c}$ animals (Figure 8, $\mathrm{A}-\mathrm{C})$. Interestingly, in situ hybridization demonstrated that the $A_{1}, A_{2 B}$, and $A_{3}$ adenosine receptors were located on inflammatory and epithelial cells in C57BL/6 and Balb/c Tg-negative and Tg-positive animals (see supplemental material; available online with this article; doi:10.1172/JCI26372DS1). In accord with the differences in inflammation in these mice, increased numbers of inflammatory cells expressing these receptors were seen in tissue sections from $\mathrm{C} 57 \mathrm{BL} / 6$ versus Balb/c Tg-positive animals (see supplemental material). When viewed in combination, these studies demonstrate that IL-4 has remarkably different effects on adenosine metabolism and adenosine receptor expression in $\mathrm{C} 57 \mathrm{BL} / 6$ versus $\mathrm{Balb} / \mathrm{c}$ animals, with the levels of adenosine and the expression of the $A_{1}, A_{2 B}$, and $\mathrm{A}_{3}$ adenosine receptors increasing while ADA activity decreases in C57BL/6, but not in Balb/c, mice.

Effects of ADA therapy. To determine if the differences in IL-4 regulation of adenosine metabolism could account for the different effects of IL- 4 in C57BL/ 6 and Balb/c animals, we treated $\operatorname{Tg}$ C57BL/6 mice with polyethylene glycol-ADA (PEG-ADA) to increase ADA activity and decrease tissue adenosine levels. These treatments decreased IL-4-induced adenosine accumulation (Figure 9A), BAL fluid and tissue inflammation (Figure 9, B and C), tissue fibrosis (Figure 9, D and E), and alveolar emphysematous remodeling (Figure 9, F-H). Interestingly, they also decreased the 


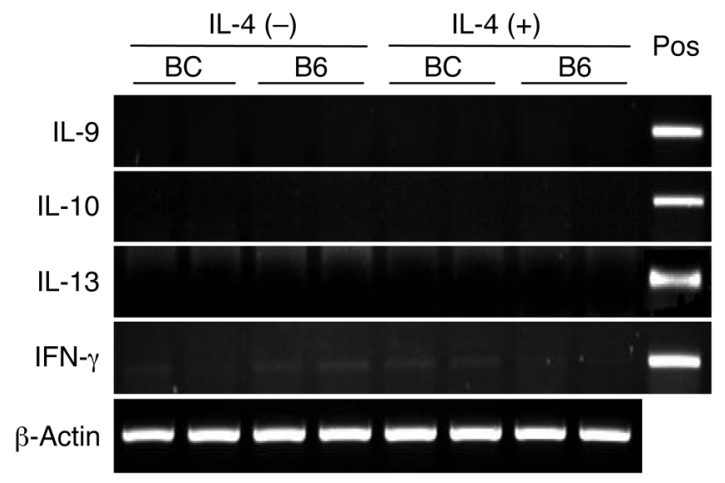

Figure 5

Effects of IL-4 on Tc1 and Tc2 cytokines. Lungs were obtained from Tgnegative and IL-4 Tg-positive mice on C57BL/6 and Balb/c backgrounds, and the levels of expression of the noted cytokines were assessed. The expression in the IL-4 Tg-positive mice is compared to the expression in positive control (pos) tissues (antigen-sensitized and -challenged murine lungs for the Th2 cytokines and CC10-rtTA-IFN- $\gamma$ Tg mice on dox water for IFN- $\gamma$ ). This panel is representative of at least 5 similar experiments.

ability of IL- 4 to inhibit $\alpha 1$-AT (Figure 9I). In accord with these observations, PEG-ADA also caused a significant increase in the survival of C57BL/6 Tg animals (Figure 10A). The PEG vehicle control did not alter the effects of IL- 4 in C57BL/ 6 mice, and ADA therapy did not cause comparable alterations in any of these parameters in Balb/c animals (data not shown). Importantly, PEG-ADA did not alter the levels of Tg IL-4 in any of these animals (Figure 10B). Thus, these studies demonstrate that treatment with PEG-ADA ameliorates the phenotype induced by Tg IL-4 in C57BL/ 6 animals and minimizes the differences between the IL-4induced responses in $\mathrm{C} 57 \mathrm{BL} / 6$ and $\mathrm{Balb} / \mathrm{c}$ mice.

\section{Discussion}

Our studies demonstrate that IL-4 has impressively different inflammatory, alveolar remodeling, and fibrotic effects in lungs from Balb/c and C57BL/ 6 mice. They also demonstrate that IL-4 differentially regulates and/or activates TIMP-2, -3 , and $-4, \alpha 1-\mathrm{AT}$, and TGF- $\beta 1$ and has impressively different effects on adenosine accumulation, ADA activity, and adenosine receptor expression in these animals. Last, they demonstrate that ADA therapy diminishes the differences between the phenotypes induced by IL-4 in Balb/c and C57BL/6 animals. When viewed in combination, these findings demonstrate that genetic factors have a profound influence on the tissue effects of IL-4 and that differences in the regulation of antiproteases and TGF- $\beta 1$ may contribute to these different responses. They also highlight impressive differences in adenosine metabolism in C57BL/6 and Balb/c mice and demonstrate that these differences contribute to the pathogenesis of the different responses that IL- 4 induces in C57BL/6 and Balb/c animals. These observations provide insights into factors that can determine whether IL-4 plays a significant or

insignificant role in the generation, severity, and/or persistence of the inflammatory and remodeling responses that occur at sites of Th2-induced pathology. In so doing, they provide at least a partial explanation for the impressive patient-to-patient and animalto-animal variability that is seen in Th2 responses in humans and animal models of human disease.

The differences in the ability of inbred murine strains to mount Th1 and/or Th2 inflammatory responses is well described in the literature, with Balb/c mice being described as Th2-prone while C57BL/6 mice are described as Th1-prone animals (4, 12-16). To date, these differences have been attributed to the differential ability of T cells from these mice to produce Th2 and/or Th1 cytokines $(4,12-15)$ with increased numbers of T cells from Balb/c mice committing to Th2 cytokine elaboration (4). To determine if there are additional layers of control of these responses, studies were undertaken to determine if inbred mice respond differently to comparable amounts of IL-4. In these experiments, care was taken to use $\mathrm{Tg}$ animals that produced levels of IL-4 that are in accord with the levels seen during the course of aeroallergen-induced Th2 pulmonary inflammation (36-38). These studies demonstrated that $\mathrm{Balb} / \mathrm{c}$ and C57BL/6 mice differ in their ability to respond to equal amounts of IL-4 and that these differences are mediated by postreceptor target cell differences between these inbred animals that do not involve STAT6 signaling. Interestingly, IL-4-induced inflammation was more pronounced in $\mathrm{C} 57 \mathrm{BL} / 6$ than in Balb/c animals. On superfi-

A

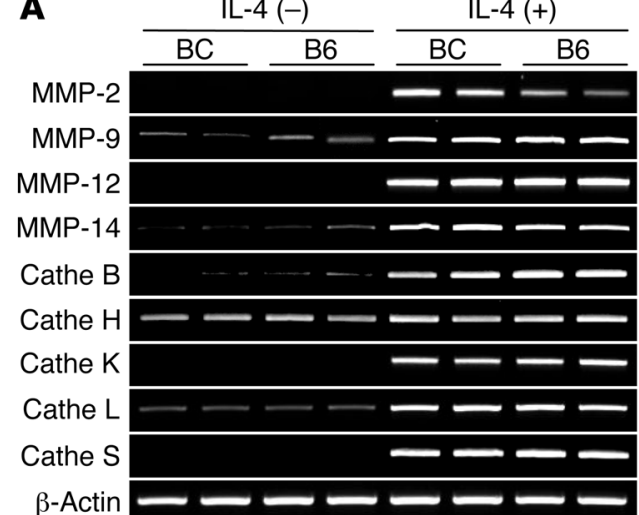

C

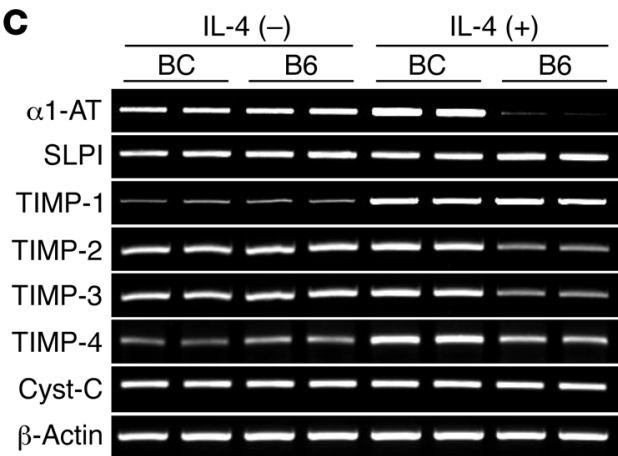

\section{Figure 6}

Effects of IL-4 on proteases and antiproteases. Lungs were obtained from Tg-negative and IL-4 Tg-positive mice on C57BL/6 and Balb/c backgrounds, and the levels of expression of the noted moieties were assessed using RT-PCR ( $\mathbf{A}$ and $\mathbf{C})$ and real-time RT-PCR ( $\mathbf{B}$ and $\mathbf{D}$ ). The data in $\mathbf{A}$ and $\mathbf{C}$ are representative of at least 5 similar experiments. The values in $\mathbf{B}$ and $\mathbf{D}$ represent the mean \pm SEM of evaluations in a minimum of 5 animals. Cathe, cathepsin. ${ }^{*} P<0.05$. 
A

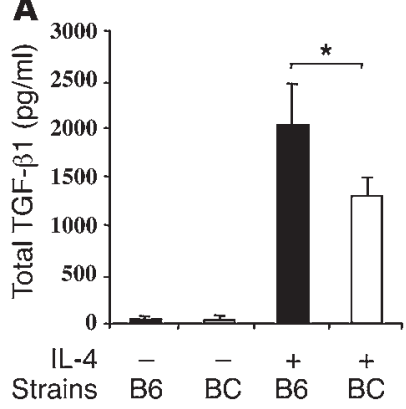

B

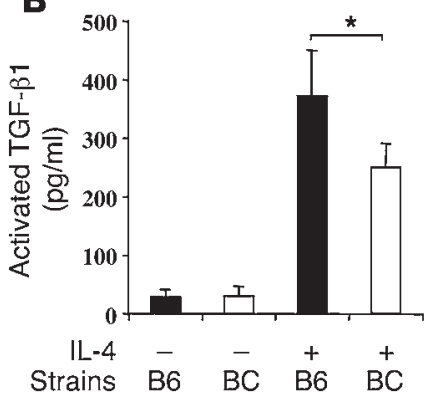

Figure 7

Effects of IL-4 on TGF- $\beta 1$. BAL fluid was obtained from lungs of Tgnegative and IL-4 Tg-positive mice on C57BL/6 and Balb/c backgrounds, and the levels of total (A) and spontaneously bioactive (B) TGF- $\beta 1$ were assessed. The values are the mean \pm SEM of evaluations in a minimum of 5 mice. ${ }^{*} P<0.05$.

cial analysis, this would appear to be contradictory to the described Th2 versus Th1 propensity of these animals. In accord with our findings, however, the eosinophilic inflammation in C57BL/6 mice is more pronounced than in $\mathrm{Balb} / \mathrm{c}$ mice after antigen sensitization and challenge in some Th2 modeling systems (14). These studies suggest that IL-4, in addition to its prominent role in the initiation of Th2 cell development, can induce greater or lesser tissue effector responses depending on the genetic context.

Although cigarette smoke is the most important cause of pulmonary emphysema in the western world, only $20 \%$ of cigarette smokers experience significant chronic obstructive pulmonary disease (COPD) (the disease spectrum that includes emphysema and chronic bronchitis). Similarly, inbred mice vary significantly in their susceptibility to cigarette smoke-induced emphysema, with AKR/J and C57BL/6 mice showing various degrees of susceptibility while NZW and Balb/c mice are resistant to this toxic insult $(8,39)$. In accord with these findings, our studies add to our understanding of the processes that regulate alveolar destruction by demonstrating that IL- 4 is a powerful stimulator of alveolar remodeling and emphysematous pulmonary destruction in C57BL/ 6 but not in Balb/c animals. These findings provide insight into the circumstances in which IL-4 could contribute to the pathogenesis of human emphysema. This may be a very important issue because IL-4 overexpression has been documented in emphysematous human lung tissues $(40,41)$ and cigarette smokeexposed murine lungs (42), and increased levels of IL-4 that correlate inversely with pulmonary function and directly with clinical manifestations have been noted in the plasma of patients with COPD (43). These observations also have implications for extrapulmonary disorders such as abdominal aortic aneurysms, where IL-4-induced Th2 responses are believed to play an essential role in disease pathogenesis (24). In both cases, disease onset, severity, and/or progression may be regulated by genetic factors that control IL-4 effector responses.

Since the mid 1960s, the protease-antiprotease hypothesis has dominated thinking as regards COPD disease pathogenesis. According to this theory, there is a balance between proteases and antiproteases in the normal lung, and an increase in proteases or a decrease in antiproteases can lead to alveolar destruction and emphysema (44, 45). To gain insight into the mechanisms that might be responsible for the enhanced emphysema in C57BL/ 6 versus Balb/c Tg mice, we characterized the expression of COPD-relevant proteases and antiproteases in these animals. Interestingly, IL-4 had comparable effects on a variety of MMPs and cathepsins. In contrast, impressively different effects on antiproteases were noted. Specifically, IL-4 inhibited $\alpha 1-\mathrm{AT}$ and TIMP-2 in C57BL/ 6 but not in Balb/c animals. In addition, IL- 4 was a less potent stimulator of TIMP- 3 and -4 in C57BL/ 6 versus $\mathrm{Balb} / \mathrm{c}$ mice. These are interesting findings because pulmonary emphysema can be caused by a genetic deficiency of $\alpha 1-\mathrm{AT}$, and the proteolytic effects of MMPs are inhibited by $\operatorname{TIMPs}(44,45)$. When viewed in combination, these findings suggest that the differences in IL-4-induced alveolar remodeling that were noted are due, at least in part, to the different antiprotease responses that are induced by IL- 4 in C57BL/ 6 and Balb/c animals.

Tissue fibrosis is a major cause of morbidity and mortality in pulmonary and extrapulmonary disorders. As a result of recent studies, the type II cytokine hypothesis has been formulated, which proposes that fibrosis occurs when cytokine balance shifts in a Th2 direction (26). Although IL-4 is known to stimulate fibroblast proliferation, myofibroblast differentiation, and collagen and proteoglycan production in experimental systems $(23,25,46,47)$, and fibroblasts at sites of Th2 inflammation express IL-4R components (48), IL-4 is not thought to be a particularly powerful fibrogenic mediator when compared with other Th2 cytokines, such as IL-13 (18, 20, 26, 27, 29). Our studies shed light on the process that may be responsible for this by demonstrating that the fibrogenic effects of IL- 4 are impressively dependent on genetic modifiers. Specifically, they demonstrate that IL-4 is a powerful stimulator of pulmonary fibrosis in C57BL/6 mice, but not in Balb/c animals. These findings are in accord with the
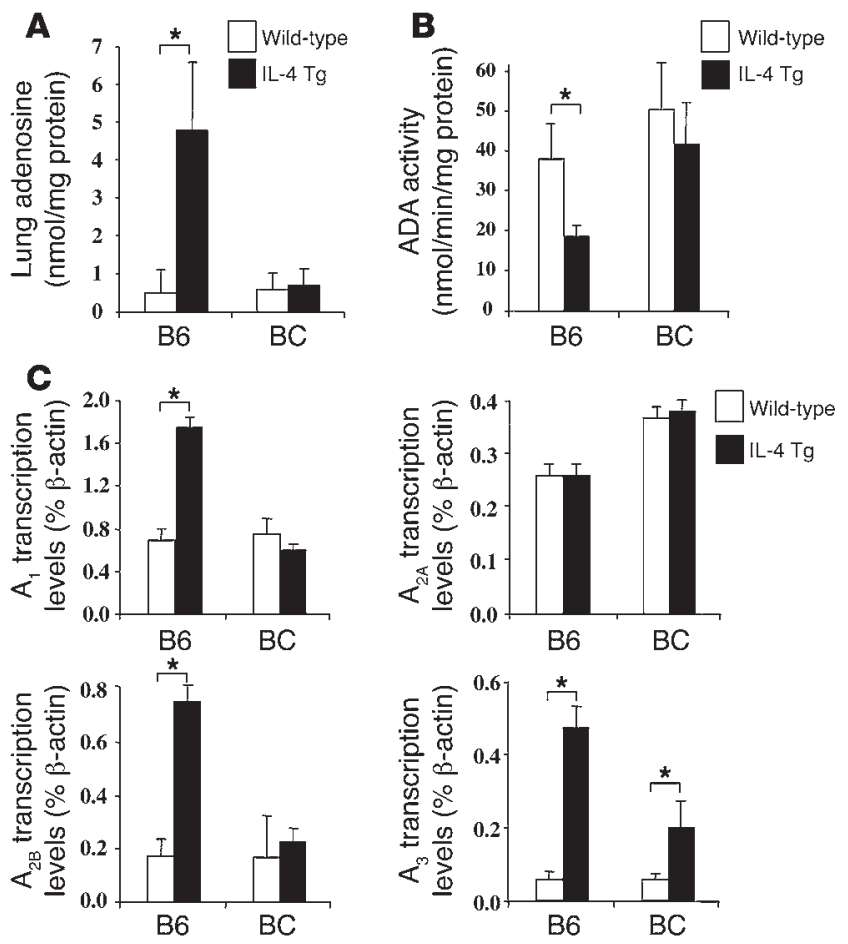

\section{Figure 8}

IL-4 regulation of adenosine metabolism and receptor expression. Lungs were obtained from 3-month-old Tg-negative (white bars) and IL-4 Tg-positive mice (black bars) on C57BL/6 and Balb/c backgrounds, and the levels of adenosine (A), ADA activity (B), and adenosine receptor expression $(\mathbf{C})$ were assessed. The values are the mean \pm SEM of evaluations in a minimum of 5 mice. ${ }^{*} P<0.01$ versus corresponding control. 
A

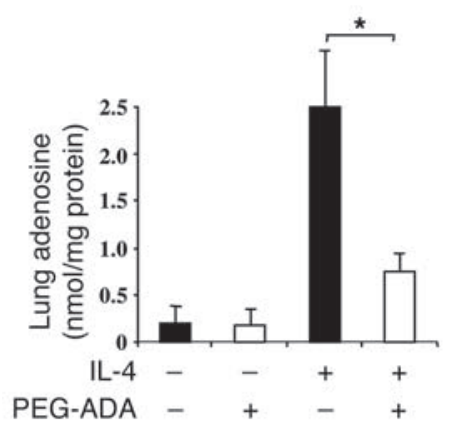

D
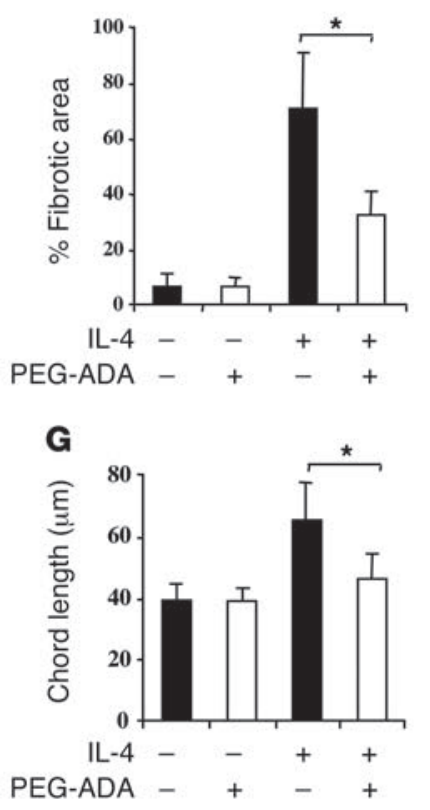

B

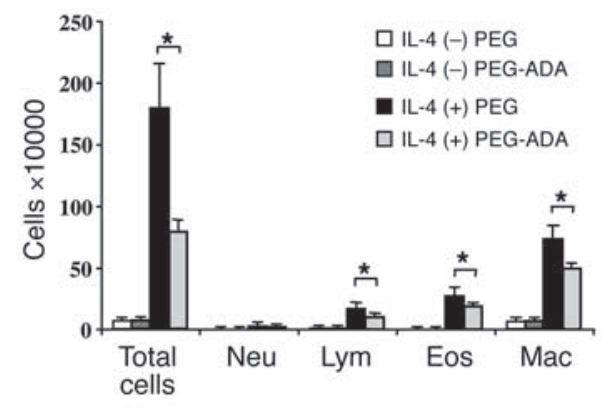

E

$(-)$

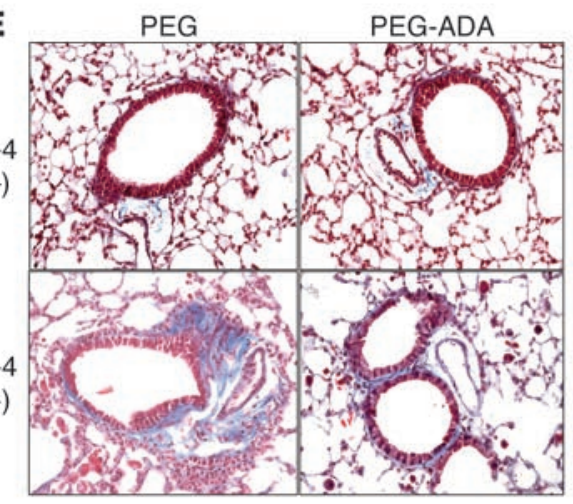

$\mathbf{H}$

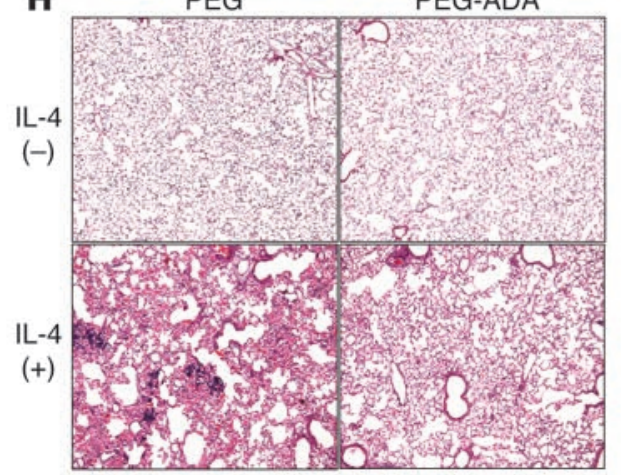

C
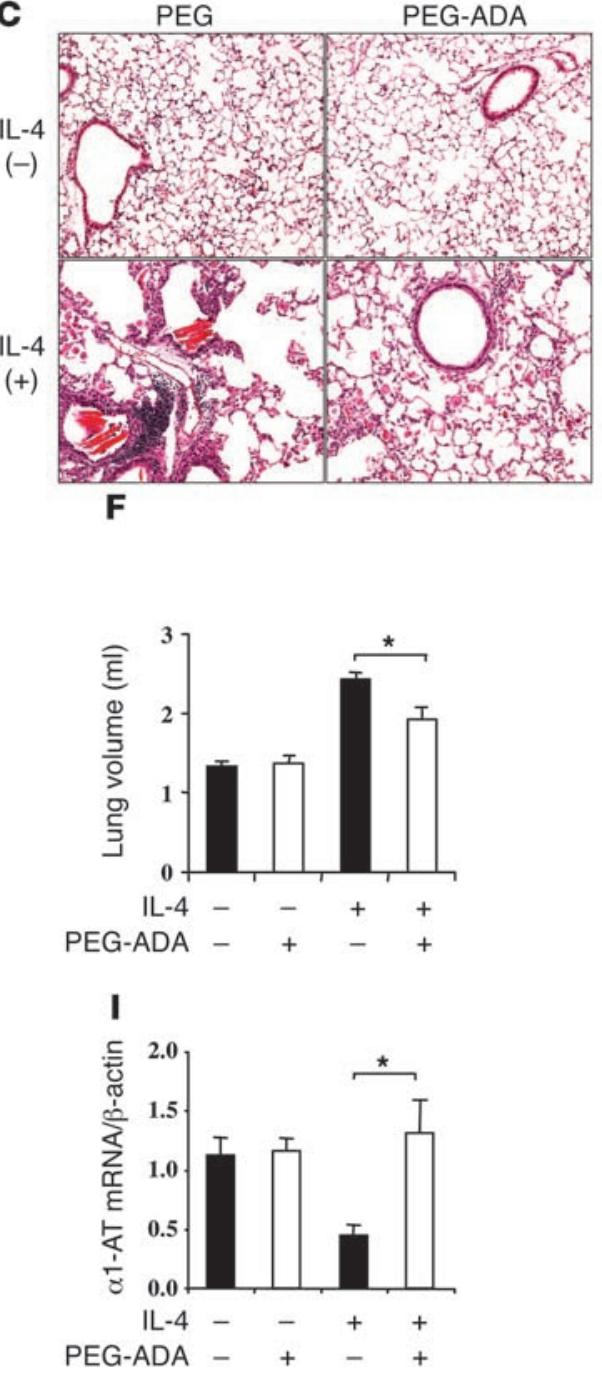

\section{Figure 9}

Effects of PEG-ADA on the phenotype induced by IL-4 in C57BL/6 mice. Tg-positive C57BL/6 mice were randomized to PEG-ADA or PEGvehicle control at 2 months of age and maintained on these regimens for an additional month. Lung adenosine content (A), total and differential BAL fluid cell recovery (B), tissue inflammation (C), collagen content (D), trichrome staining (E), lung volume (F), alveolar chord length (G), alveolar histology $(\mathbf{H})$, and real-time RT-PCR evaluations of $\alpha 1$-AT mRNA (I) were assessed. C, E, and $\mathbf{H}$ are representative of at least 5 similar experiments. The values in the rest of the figures represent the mean \pm SEM of experiments with a minimum of 5 animals. ${ }^{*}<0.01$. Original magnification, $\times 10(\mathbf{C}) ; \times 20(\mathbf{E}) ; \times 4(\mathbf{H})$.

fibrogenic capacity of other stimuli, such as bleomycin and radiation in these inbred murine strains $(3,5,10,11,49)$. Our studies also demonstrate that IL-4 is a more powerful stimulator and activator of the powerful fibrogenic mediator TGF- $\beta 1$ in $\mathrm{C} 57 \mathrm{BL} / 6$ than in $\mathrm{Balb} / \mathrm{c}$ animals. This suggests that these different effects of IL-4 are due in part to the differential ability of IL- 4 to stimulate and activate TGF- $\beta 1$ in these inbred animals. It is important to point out, however, that the differences in collagen accumulation that were noted exceeded the differences in TGF- $\beta 1$ production and activation that were seen. This raises the possibility that other cellular and molecular events may also contribute to the differential fibrotic effects of IL- 4 in these different genetic settings.
Adenosine is a nucleoside that is generated by ATP catabolism at sites of tissue stress and injury that signals via $G$ protein-coupled receptors that regulate a wide array of physiologic and immune responses (50-56). Elevated levels of adenosine are found in BAL fluids from patients with asthma (57), and adenosine regulates the functions of a number of cell types central to Th2 responses, including eosinophils, mast cells, and smooth muscle cells $(51,58,59)$. Aerosol adenosine exposure also induces bronchospasm in patients with asthma and COPD but not in normal controls $(60,61)$. The present studies demonstrate that IL-4 stimulates tissue adenosine accumulation, inhibits ADA activity, and enhances the expression of the $A_{1}, A_{2 B}$, and $A_{3}$ ade- 


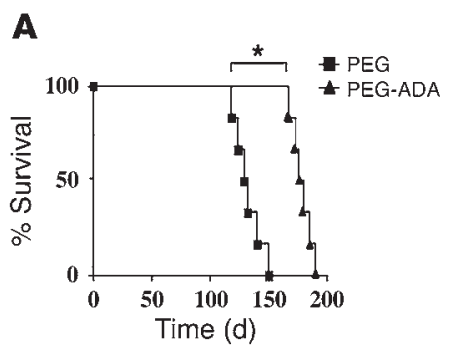

Figure 10

Effects of PEG-ADA on the survival of and IL-4 production in Tg-positive C57BL/6 mice. (A) Tg-positive mice were randomized to PEG-ADA or PEG-vehicle control at 2 months of age and survival was assessed. (B) Tg-positive mice were randomized to PEG-ADA or PEG-vehicle control at 2 months of age and maintained on this regimen for 1 month. The levels of BAL IL-4 were then quantitated. The values represent the mean \pm SEM of experiments with a minimum of 5 animals at each time point. ${ }^{*} P<0.01$.

nosine receptors in $\mathrm{C} 57 \mathrm{BL} / 6$ but not in Balb/c animals. These studies also demonstrate that these alterations play a key role in the pathogenesis of the differential effector functions of IL-4 in these inbred murine stains because ADA therapy decreased the levels of IL-4-induced inflammation, alveolar remodeling, and tissue fibrosis in C57BL/ 6 animals to levels that approximated those in Balb/c animals. This is, to our knowledge, the first demonstration that adenosine plays an important role in the pathogenesis of these key IL-4 effector activities and the first demonstration that genetic factors regulate tissue adenosine metabolism. We previously demonstrated that interventions that increased the levels of tissue adenosine generated a phenotype that is similar in many ways to the responses in asthma and COPD, including eosinophil- and macrophage-rich inflammation, alveolar enlargement, airway remodeling, mucus metaplasia, airways hyperresponsiveness, and tissue fibrosis (62). We also demonstrated that IL-13 is a powerful stimulator of tissue adenosine accumulation and that this increase in adenosine is an essential contributor to the pathogenesis of IL-13-induced tissue alterations (51). The present studies demonstrate that IL-4 has similar effects on adenosine metabolism and induces similar tissue responses in $\mathrm{C} 57 \mathrm{BL} / 6$ but not in Balb/c mice. This raises the interesting possibility that, in appropriate genetic circumstances, IL-4-induced alterations in adenosine metabolism may be an essential part of Th2 inflammatory and remodeling responses.

In summary, these studies demonstrate that genetic factors can modify IL-4 effector responses, resulting in qualitatively and quantitatively different inflammatory, destructive, and fibrotic tissue responses. They also highlight the importance of differences in antiprotease induction and adenosine metabolism in the pathogenesis of these different tissue responses. Since IL-4, antiprotease, and adenosine dysregulation are well documented in COPD and asthma and other Th2 disorders, it is tempting to speculate that similar genetic modifiers are responsible for the variable presentations, natural histories, and responses to therapy that clinicians see in caring for patients with these disorders. Additional investigations of the genes that mediate and the mechanisms that are responsible for the different responses induced by IL-4 in inbred mice and their relevance in humans are warranted.

\section{Methods}

$\mathrm{Balb} / \mathrm{c}$ and C57BL/6 IL-4 Tg mice. Studies were conducted using CC10-IL-4 $\mathrm{Tg}$ mice. These mice use the rat CC10 promoter to overexpress murine IL-4 in a lung-specific fashion (18). They produce levels of IL-4 that are comparable to those seen during the course of aeroallergen-induced pulmonary Th2 inflammatory responses (36-38). These mice were bred for more than 10 generations onto $\mathrm{Balb} / \mathrm{c}$ and $\mathrm{C} 57 \mathrm{BL} / 6$ genetic backgrounds. Non-Tg littermates were used as controls. Genotyping was conducted by screening genomic DNA isolated from tail biopsies using PCR as previously described (18). These studies were approved by the Yale University School of Medicine Institutional Animal Care and Use Committee.

Breeding of Tg mice. Balb/c IL-4 Tg-positive mice were bred serially with wild-type C57BL/ 6 animals (Jackson Laboratory). After each passage, genotyping was undertaken and lung phenotypes were evaluated.

$B A L$. Mice were euthanized, the trachea was isolated by blunt dissection, and a small caliber tube was inserted into the airway and secured. Two volumes of $1 \mathrm{ml}$ of PBS with $0.1 \%$ BSA were instilled and gently aspirated and pooled (BAL fluid). Samples were centrifuged for 5 minutes to recover cells, and the supernatants from these spins were collected and stored at $-70^{\circ} \mathrm{C}$ for further analysis. Cell pellets were resuspended in PBS and total cell counts determined using a hemocytometer. Aliquots were cytospun onto microscope slides and stained for cellular differentials.

$m R N A$ analysis. RNA was isolated from frozen lungs using TRIzol Reagent (Invitrogen Corp.) according to manufacturer's instructions. RNA samples were then DNase treated and subjected to either semiquantitative or quantitative real-time RT-PCR using primers and approaches that have been previously described by our laboratory $(27,32,51)$ and the primers outlined in Supplemental Table 1.

Western blot analysis. Protease protein was evaluated by Western blot analysis as previously described by our laboratory $(32,63)$.

Histology. Tissues were fixed overnight in $10 \%$ buffered formalin. After washing in fresh PBS, fixed tissues were dehydrated, cleared, and embedded in paraffin by routine methods. Sections $(5 \mu \mathrm{m})$ were collected, deparaffinized, and stained with H\&E or Mallory's trichrome as described previously $(33,64)$.

Assessment of lung volume and alveolar size. To evaluate the effects of IL-4 on parameters of alveolar remodeling, lung volume and alveolar size were evaluated as previously described by our laboratory (32). For the volume measurements, the animals were anesthetized, the trachea was cannulated, and the lungs were degassed. The lungs and heart were then removed en bloc and inflated with PBS at $25 \mathrm{~cm}$ of pressure. The size of the lung was evaluated via volume displacement.

Alveolar size was estimated from the mean chord length of the airspace. This is a morphometric quantification of the mean distance between the walls of the alveoli. This method was chosen because, in contrast to the alternative, the mean linear intercept, it is independent of alveolar septal thickness. In these evaluations, sections were prepared as described above, and images were acquired into a Macintosh computer through a frame grabber board in 8-bit grayscale at a final magnification of 1.5 pixels per micron. Images were analyzed using the public domain NIH Image program (http://rsb.info.nih.gov/ nih-image) and also using a custom-written macro available from the web site (ChordLength.SurfaceArea; ftp://rsbweb.nih.gov/pub/nih-image/contrib/). Images were manually thresholded, then smoothed and inverted. They were then subjected to sequential logical image match and analyzed with horizontal and vertical grids, and mean chord length was calculated.

Quantification of lung collagen. Lung collagen content was determined by quantifying total soluble collagen using the Sircol Collagen Assay kit (Biocolor Ltd.) and with quantitative Sirius red evaluations as previously described by our laboratory $(33,64)$.

Generation of CC10-rtTA-IL-4 mice. CC10-rtTA-IL-4 mice were generated in which the CC10 protein promoter and 2 Tg constructs target IL-4 
to the murine lung in an externally regulatable fashion. The CC10-rtTA $\mathrm{Tg}$ system and the constructs that were employed have been described previously by our laboratory (32). Construct 1, CC10-rtTA-hGH, contains the CC10 promoter, rtTA, and human growth hormone (hGH) intronic and polyadenylation sequences. The rtTA is a fusion protein made up of a mutated tetracycline repressor (rtet-R) and the herpesvirus VP-16 transactivator. Construct 2, tet-O-CMV-IL-13-hGH, contains a polymeric tetracycline operator (tet-O), minimal CMV promoter, murine IL-4 cDNA, and hGH intronic and adenylation signals. In this system, the CC10 promoter directs the expression of rtTA to the lung. In the presence of doxycycline (dox), rtTA is able to bind in trans to the tet-O, and the VP-16 transactivator activates IL-4 gene transcription. In the absence of dox, rtTA binding occurs at very low levels, and low level or no gene transcription is noted. The preparation of the CC10-rtTA construct has been previously described. The tet-O-CMV-IL-4 construct was prepared by replacing the IL- 13 cDNA in the construct tet-O-CMV-hIL-13 previously described by our laboratory (32) with the murine IL-4 cDNA. This construct was checked for correct insert orientation by restriction enzyme digestion and sequencing. Simultaneous microinjection was undertaken as previously described (32).

The presence or absence of the Tgs was initially evaluated using Southern blot analysis and later by PCR. Southern blot analysis was performed as previously described using cDNA encoding murine IL-4 or rtTA. PCR for rtTA was also performed using protocols described by our laboratory (32). All CC10-rtTA-IL-13 lineage animals were evaluated for the presence of both the rtTA- and IL-4-containing Tg constructs.

CC10-rtTA-IL-4 animals were maintained on normal water until 1 month of age. At that time, they were randomized to normal water or water containing dox $(0.5 \mathrm{mg} / \mathrm{ml})$ as previously described (32).

STAT6 evaluations. The levels of total and phosphorylated STAT6 were evaluated using Western blot analyses as previously described by our laboratory (65).

Adenosine quantification. Mice were anesthetized, a median sternotomy was undertaken, and the lungs were rapidly removed and frozen in liquid nitrogen. Adenine nucleosides were extracted from frozen lung tissue using $0.4 \mathrm{~N}$ perchloric acid, and adenosine was separated and quantified using reversed-phase HPLC as previously described (51).
Analysis of ADA enzyme activity. The levels of ADA enzyme activity in serum and tissues were measured using zymogram analysis and a spectrophometric enzymatic assay, following established procedures (66).

In situ bybridization of adenosine receptors. To localize the $\mathrm{A}_{1}, \mathrm{~A}_{2 \mathrm{~B}}$, and $\mathrm{A}_{3}$ adenosine receptors, in situ hybridization was undertaken as previously described by our laboratories (51)

ADA enzyme therapy. PEG-modified ADA (PEG-ADA) was prepared in our laboratories and administered ( $15 \mathrm{U}$ every 4 days) via an intranasal route as previously described $(51,62)$. In the experiments in which inflammation, fibrosis, and/or remodeling were being assessed, intranasal injections were started when the animals were 2 months of age, and the animals were sacrificed when they were 3 months old. For the survival studies, intranasal injections were started in 2-month-old animals and continued until the animals died or were 6 months old.

IL-4 and TGF- $\beta 1$ quantification. The levels of BAL IL-4 and TGF- $\beta 1$ were assessed by ELISA with kits (R\&D Systems) per the manufacturer's instructions. The TGF- $\beta 1$ evaluations were undertaken before and after acid activation to evaluate spontaneously bioactive and total TGF- $\beta 1$, respectively.

Statistics. Normally distributed data are expressed as mean \pm SEM and were assessed for significance using the 2-tailed Student's $t$ test or ANOVA as appropriate. Data that were not normally distributed were assessed for significance using the Wilcoxon Rank Sum test or the Kruskal-Wallis test. $P$ values less than 0.05 were considered statistically significant.

\section{Acknowledgments}

The authors wish to thank the individuals and institutions that provided the reagents that were employed and Suping Chen and Kathleen Bertier for their excellent technical and administrative assistance.

Received for publication July 22, 2005, and accepted in revised form February 21, 2006.

Address correspondence to: Jack A. Elias, Section of Pulmonary and Critical Care Medicine, Yale University School of Medicine, 300 Cedar Street, S441 The Anylan Center, New Haven, Connecticut 06519, USA. Phone: (203) 785-4163; Fax: (203) 785-3826; E-mail: jack.elias@yale.edu.
1. Hamilton, B.A., and Frankel, W.N. 2001. Of mice and genome sequence. Cell. 107:13-16.

2. Anderson, C.F., Mendez, S., and Sacks, D.L. 2005. Nonhealing infection despite Th1 polarization produced by a strain of Leishmania major in C57BL/ 6 mice. J. Immunol. 174:2934-2941.

3. Barth, R.K., Hanchett, L.A., and Baecher-Allan, C.M. 2002. Mapping susceptibility genes for the induction of pulmonary fibrosis in mice. Chest. 121:21S.

4. Bix, M., Wang, Z.E., Thiel, B., Schork, N.J., and Locksley, R.M. 1998. Genetic regulation of commitment to interleukin 4 production by a CD4(+) T cell-intrinsic mechanism. J. Exp. Med. 188:2289-2299.

5. Bonniaud, P., et al. 2004. Connective tissue growth factor is crucial to inducing a profibrotic environment in "fibrosis-resistant" BALB/c mouse lungs. Am.J. Respir. Cell Mol. Biol. 31:510-516.

6. De Sanctis, G.T., et al. 1995. Quantitative locus analysis of airway hyperresponsiveness in A/J and C57BL/6J mice. Nat. Genet. 11:150-154.

7. Duguet, A., et al. 2000. Bronchial responsiveness among inbred mouse strains. Role of airway smooth-muscle shortening velocity. Am. J. Respir. Crit. Care Med. 161:839-848.

8. Guerassimov, A., et al. 2004. The development of emphysema in cigarette smoke-exposed mice is strain dependent. Am. J. Respir. Crit. Care Med.
170:974-980

9. Haston, C.K., Corey, M., and Tsui, L.C. 2002. Mapping of genetic factors influencing the weight of cystic fibrosis knockout mice. Mamm. Genome. 13:614-618.

10. Haston, C.K., and Travis, E.L. 1997. Murine susceptibility to radiation-induced pulmonary fibrosis is influenced by a genetic factor implicated in susceptibility to bleomycin-induced pulmonary fibrosis. Cancer Res. 57:5286-5291.

11. Haston, C.K., et al. 2002. Universal and radiationspecific loci influence murine susceptibility to radiation-induced pulmonary fibrosis. Cancer Res. 62:3782-3788.

12. Charles, P.C., Weber, K.S., Cipriani, B., and Brosnan, C.F. 1999. Cytokine, chemokine and chemokine receptor mRNA expression in different strains of normal mice: implications for establishment of a Th1/Th2 bias. J. Neuroimmunol. 100:64-73.

13. Fan, T., Yang, M., Halayko, A., Mohapatra, S.S., and Stephens, N.L. 1997. Airway responsiveness in two inbred strains of mouse disparate in IgE and IL-4 production. Am. J. Respir. Cell Mol. Biol. 17:156-163.

14. Takeda, K., Haczku, A., Lee, J.J., Irvin, C.G., and Gelfand, E.W. 2001. Strain dependence of airway hyperresponsiveness reflects differences in eosinophil localization in the lung. Am. J. Physiol. Lung Cell. Mol. Physiol. 281:L394-L402.

15. Takeshita, K., Yamasaki, T., Akira, S., Gantner, F., and Bacon, K.B. 2004. Essential role of MHC IIindependent CD4+ T cells, IL-4 and STAT6 in contact hypersensitivity induced by fluorescein isothiocyanate in the mouse. Int. Immunol. 16:685-695.

16. Zhang, Y., et al. 1997. Influence of the route of allergen administration and genetic background on the murine allergic pulmonary response. Am. J. Respir. Crit. Care Med. 155:661-669.

17. Snapper, C.M., and Paul, W.E. 1987. Interferongamma and B cell stimulatory factor- 1 reciprocally regulate Ig isotype production. Science. 236:944-947.

18. Rankin, J.A., et al. 1996. Phenotypic and physiologic characterization of transgenic mice expressing interleukin 4 in the lung: lymphocytic and eosinophilic inflammation without airway hyperreactivity. Proc. Natl. Acad. Sci. U. S. A. 93:7821-7825.

19. Voehringer, D., Shinkai, K., and Locksley, R.M. 2004. Type 2 immunity reflects orchestrated recruitment of cells committed to IL-4 production. Immunity. 20:267-277.

20. Richter, A., et al. 2001. The contribution of interleukin (IL)-4 and IL-13 to the epithelial-mesenchymal trophic unit in asthma. Am. J. Respir. Cell Mol. Biol. 25:385-391.

21. Jain-Vora, S., Wert, S.E., Temann, U.A., Rankin, J.A., and Whitsett, J.A. 1997. Interleukin-4 alters epithelial cell differentiation and surfactant homeostasis in the postnatal mouse lung. Am. J. Respir. Cell Mol. 
Biol. 17:541-551.

22. Leigh, R., et al. 2004. Type 2 cytokines in the pathogenesis of sustained airway dysfunction and airway remodeling in mice. Am. J. Respir. Crit. Care Med. 169:860-867.

23. Saito, A., Okazaki, H., Sugawara, I., Yamamoto, K., and Takizawa, H. 2003. Potential action of IL-4 and IL-13 as fibrogenic factors on lung fibroblasts in vitro. Int. Arch. Allergy Immunol. 132:168-176.

24. Shimizu, K., Shichiri, M., Libby, P., Lee, R.T., and Mitchell, R.N. 2004. Th2-predominant inflammation and blockade of IFN- $\gamma$ signaling induce aneurysms in allografted aortas. J. Clin. Invest. 114:300-308. doi:10.1172/JCI200419855.

25. Leonardi, A., et al. 2003. Effects of Th2 cytokines on expression of collagen, MMP-1, and TIMP-1 in conjunctival fibroblasts. Invest. Ophthalmol. Vis. Sci. 44:183-189.

26. Wynn, T.A. 2004. Fibrotic disease and the Th1/Th2 paradigm. Nat. Rev. Immunol. 4:583-594.

27. Zhu, Z., et al. 1999. Pulmonary expression of interleukin-13 causes inflammation, mucus hypersecretion, subepithelial fibrosis, physiologic abnormalities and eotaxin production. J. Clin. Invest. 103:779-788.

28. Elias, J.A., et al. 2003. New insights into the pathogenesis of asthma. J. Clin. Invest. 111:291-297. doi:10.1172/JCI200419855.

29. Wills-Karp, M., and Chiaramonte, M. 2003. Interleukin-13 in asthma. Curr. Opin. Pulm. Med. 9:21-27.

30. Burri, P.H. 1997. Structural aspects of prenatal and postnatal development and growth of the lung. In Lung growth and development. J.A. McDonald, editor. Marcel Dekker Inc. New York, New York, USA. 1-35.

31. Ray, P., et al. 1997. Regulated overexpression of interleukin-11 in the lung: use to dissociate development-dependent and -independent phenotypes. J. Clin. Invest. 100:2501-2511.

32. Zheng, T., et al. 2000. Inducible targeting of IL-13 to the adult lung causes matrix metalloproteinaseand cathepsin-dependent emphysema. J. Clin. Invest. 106:1081-1093.

33. Lee, C.G., et al. 2002. Transgenic overexpression of interleukin (IL)-10 in the lung causes mucus metaplasia, tissue inflammation, and airway remodeling via IL-13-dependent and -independent pathways. J. Biol. Chem. 277:35466-35474.

34. Temann, U.A., Ray, P., and Flavell, R.A. 2002. Pulmonary overexpression of IL-9 induces Th2 cytokine expression, leading to immune pathology. J. Clin. Invest. 109:29-39. doi:10.1172/JCI200213696.

35 . Wang, Z., et al. 2000. Interferon gamma induction of pulmonary emphysema in the adult murine lung. J. Exp. Med. 192:1587-1600.

36. Kwak, Y.G., et al. 2003. Involvement of PTEN in airway hyperresponsiveness and inflammation in bronchial asthma. J. Clin. Invest. 111:1083-1092. doi:10.1172/JCI200316440.
37. Wang, J., Homer, R.J., Chen, Q., and Elias, J.A. 2000. Endogenous and exogenous IL- 6 inhibit aeroallergen-induced Th2 inflammation. J. Immunol. 165:4051-4061.

38. Wang, J., et al. 2000. IL-11 selectively inhibits aeroallergen-induced pulmonary eosinophilia and Th2 cytokine production. J. Immunol. 165:2222-2231.

39. Shapiro, S.D. 2000. Animal models for COPD. Chest. 117:223S-227S.

40. Jeffery, P.K. 1999. Differences and similarities between chronic obstructive pulmonary disease and asthma. Clin. Exp. Allergy. 29:14-26.

41. Jeffery, P.K. 2001. Lymphocytes, chronic bronchitis and chronic obstructive pulmonary disease. Novartis Found. Symp. 234:149-168.

42. Bartalesi, B., et al. 2005. Different lung responses to cigarette smoke in two strains of mice sensitive to oxidants. Eur. Respir. J. 25:15-22.

43. Zhang, N., et al. 1999. Effects of theophylline on plasma levels of interleukin-4, cyclic nucleotides and pulmonary functions in patients with chronic obstructive pulmonary disease. J. Tongji Med. Univ. 19:15-19.

44. Sutherland, E.R., and Cherniack, R.M. 2004. Management of chronic obstructive pulmonary disease. N. Engl. J. Med. 350:2689-2697.

45. Senior, R.M., and Shapiro, S.D. 1998. Chronic obstructive pulmonary disease: epidemiology, pathophysiology, and pathogenesis. In Fishman's pulmonary diseases and disorders. A.P. Fishman et al., editors. McGraw-Hill Inc. New York, New York, USA. 659-681.

46. Hashimoto, S., Gon, Y., Takeshita, I., Maruoka, S., and Horie, T. 2001. IL-4 and IL-13 induce myofibroblastic phenotype of human lung fibroblasts through c-Jun NH2-terminal kinase-dependent pathway. J. Allergy Clin. Immunol. 107:1001-1008.

47. Hashimoto-Uoshima, M., et al. 2002. Effects of interleukin-4 on proteoglycan accumulation in human gingival fibroblasts. J. Periodont. Res. 37:42-49.

48. Steinke, J.W., et al. 2004. Characterization of interleukin-4-stimulated nasal polyp fibroblasts. Am. J. Respir. Cell Mol. Biol. 30:212-219.

49. Kolb, M., et al. 2002. Differences in the fibrogenic response after transfer of active transforming growth factor-beta1 gene to lungs of "fibrosisprone" and "fibrosis-resistant" mouse strains. Am. J. Respir. Cell Mol. Biol. 27:141-150.

50. Belardinelli, L., Linden, J., and Berne, R.M. 1989. The cardiac effects of adenosine. Prog. Cardiovasc. Dis. 32:73-97.

51. Blackburn, M.R., et al. 2003. Adenosine mediates IL-13-induced inflammation and remodeling in the lung and interacts in an IL-13-adenosine amplification pathway. J. Clin. Invest. 112:332-344. doi:10.1172/JCI200316815.

52. Churchill, P.C. 1982. Renal effects of 2-chloroadenosine and their antagonism by aminophylline in anesthetized rats. J. Pharmacol. Exp. Ther.
222:319-323

53. Fredholm, B.B., and Dunwiddie, T.V. 1988. How does adenosine inhibit transmitter release? Trends Pharmacol. Sci. 9:130-134.

54. Huang, S., Apasov, S., Koshiba, M., and Sitkovsky, M. 1997. Role of A2a extracellular adenosine receptor-mediated signaling in adenosine-mediated inhibition of T-cell activation and expansion. Blood. 90:1600-1610.

55. Ohta, A., and Sitkovsky, M. 2001. Role of G-protein-coupled adenosine receptors in downregulation of inflammation and protection from tissue damage. Nature. 414:916-920.

56. Tilley, S.L., Wagoner, V.A., Salvatore, C.A., Jacobson, M.A., and Koller, B.H. 2000. Adenosine and inosine increase cutaneous vasopermeability by activating $\mathrm{A}(3)$ receptors on mast cells. J. Clin. Invest. 105:361-367.

57. Driver, A.G., Kukoly, C.A., Ali, S., and Mustafa, S.J. 1993. Adenosine in bronchoalveolar lavage fluid in asthma. Am. Rev. Respir. Dis. 148:91-97.

58. Marquardt, D.L., Parker, C.W., and Sullivan, T.J. 1978. Potentiation of mast cell mediator release by adenosine. J. Immunol. 120:871-878.

59. Walker, B.A., et al. 1997. Adenosine A3 receptor expression and function in eosinophils. Am. J. Respir. Cell Mol. Biol. 16:531-537.

60. Cushley, M.J., Tattersfield, A.E., and Holgate, S.T. 1983. Inhaled adenosine and guanosine on airway resistance in normal and asthmatic subjects. $\mathrm{Br}$. J. Clin. Pharmacol. 15:161-165.

61. Oosterhoff, Y., de Jong, J.W., Jansen, M.A., Koeter, G.H., and Postma, D.S. 1993. Airway responsiveness to adenosine $5^{\prime}$-monophosphate in chronic obstructive pulmonary disease is determined by smoking. Am. Rev. Respir. Dis. 147:553-558.

62. Blackburn, M.R., et al. 2000. Metabolic consequences of adenosine deaminase deficiency in mice are associated with defects in alveogenesis, pulmonary inflammation, and airway obstruction. J. Exp. Med. 192:159-170.

63. Zheng, T., et al. 2005. Role of cathepsin S-dependent epithelial cell apoptosis in IFN-gammainduced alveolar remodeling and pulmonary emphysema. J. Immunol. 174:8106-8115.

64. Lee, C.G., et al. 2004. Early growth response gene 1-mediated apoptosis is essential for transforming growth factor beta1-induced pulmonary fibrosis. J. Exp. Med. 200:377-389.

65. Lee, P.J., et al. 2006. ERK1/2 mitogen-activated protein kinase selectively mediates IL-13-induced lung inflammation and remodeling in vivo. J. Clin. Invest. 116:163-173. doi:10.1172/JCI25711.

66. Winston, J.H., Hanten, G.R., Overbeek, P.A., and Kellems, R.E. 1992. 5' flanking sequences of the murine adenosine deaminase gene direct expression of a reporter gene to specific prenatal and postnatal tissues in transgenic mice. J. Biol. Chem. 267:13472-13479. 